\section{Facilitation of foveal letter recognition by metacontrast*}

\author{
MICHAEL L. MATTHEWS and LESLIE HENDERSON \\ University of Guelph, Guelph, Ont., Canada
}

Foveal letter recognition is improved in the presence of a flanking letter context. Signal detection analysis is used to examine sensitivity changes attributable to specific contour interactions between target and context letters.

The processing of a single letter from a row has been found to be affected by other letters in that row. In a short-term memory paradigm, Averbach \& Coriell (1961) have demonstrated that a "W"-shaped distribution describes recognition probabilities of individual letters in a row; that is, the middle and end letters have a higher probability of recall than do intermediate letters. It has since been concluded (Haber \& Standing, 1969; Coltheart \& Merikle, 1970) that two factors are responsible for the shape of the function: increasing distance from the foveal fixation gives poorer acuity, and metacontrast occurs between letters, where metacontrast describes a situation in which the perception of a given letter is somehow reduced by having letters on either side of it. The plausibility of the latter assumption has gained strength from the results of Haber \& Standing (1969), who found that the elevated probabilities of recalling end letters in a row could be reduced by the addition of parentheses to the ends of the array. In this case, it appears as if the parentheses act as additional letters and reduce performance accordingly. This confirms Woodworth's (1948) suggestion that masking occurs between adjacent letters presented in peripheral vision.

Both of these studies require explanations based upon the perception, rather than the retention, of the letter row. With respect to acuity for letters, a systematic decrease in resolution with increasing eccentricity has been reported (Ruediger, 1907; Weymouth, 1958), although it should be pointed out that there is currently little evidence for such systematic changes across the small angular extent that is typically used in memory experiments. Relevant data on metacontrast using this paradigm comes from Bouma (1970), who has shown that recognition of a peripherally presented letter is impaired when a further letter is added to each side. This impairment is found

* This research was supported by grants from the National Research Council and Defense Research Board of Canada and was carried out in part at the Defense Research Establishment, Toronto. to increase with greater distances from the fovea. However, Bouma's study did not extend to foveal regions, and his psychophysical procedure did not exclude the effects of nonsensory variables on his results. Further data on metacontrast in the fovea comes from Flom, Weymouth, \& Kahneman (1963), who found that acuity for a Landolt $C$ was impaired when surrounding bars or letters, " $E$," were introduced.

The aim of the present study was to examine the effects of introducing adjacent letters on foveal single letter recognition and to determine whether the effects were related to physical features (contour) or to linguistically coded features of the letters, whether or not the number of adjacent letters was important, and finally, whether the effects were attributable to sensory or criterial changes.

$$
\text { METHOD }
$$

A Scientific Prototype Model GB three-channel tachistoscope was used in these experiments. Field 1 was uniformly illuminated at a luminance of $28 \mathrm{fL}$ and contained a central circular fixation mark, $3 \mathrm{~min}$ in diam. In Field 2, uppercase letters, A, E, O, or $U$, could be presented singly at a central aperture as black stimuli on a white ground, uniformly illuminated at $14 \mathrm{fL}$. Field 3, with a luminance of $14 \mathrm{fL}$, contained a horizontal row of eight uppercase $\mathrm{Os}$, $\mathrm{Hs}$, or $\mathrm{Xs}$ or a blank card (for the target-alone condition). A space between the fourth and fifth letters was such that, when Fields 2 and 3 were simultaneously illuminated, the single letter from Field 2 appeared centered in the row of letters in Field 3 . The luminance of all the letters was $15 \mathrm{fL}$. The Field 2 Tetter was the "target," and the letters in Field 3 were designated the "context." This system enabled us to present the $S$ with a target alone or a target in a contextual row. Flash durations generated by the tachistoscope were calibrated with a U.D.T. Pin 10 silicon photodiode, in conjunction with a dc amplifier. Ninety-five percent of flash durations fell within an accuracy of $6 \%$. The luminances of the fields were monitored constantly throughout the experiment.
The letters used were all Letraset 28-point Helvetica Medium transferred to white cards. The angular dimensions of the letters, at the viewing distance of $50 \mathrm{in.}$, were as follows: target letters were all 22 min high, $O$ and $A$ were $20 \mathrm{~min}$ wide, E, $16 \mathrm{~min}$ wide, and $U, 17.5 \mathrm{~min}$. wide. The overall length of the contextual stimulus was $3.3 \mathrm{deg}$ for the Os and $3.05 \mathrm{deg}$ for the $\mathrm{Hs}$ and Xs. The minimum distance between adjacent contours of the fourth and fifth letters of the context was $23 \mathrm{~min}$ for the Os and $\mathrm{Hs}$ and $24.5 \mathrm{~min}$ for the Xs. Thus, when the target letter was presented simultaneously with the context, the angular separation between the closest contours of the target and central context letters was between 1.5 and $4.25 \mathrm{~min}$, depending on the exact combination of target and context.

The following procedure was used: At a ready signal from $E, S$ depressed. a hand-held button in his own time. This extinguished the adapting field and illuminated the target field. $S$ then reported the letter seen, a four-alternative forced choice. At the offset of Field 2, the adapting field was again seen after an 0.5 -sec delay.

For an experimental run, the four targets were presented 10 times each in random order at a given Field 2 duration. In all conditions, Fields 2 and 3 were driven by the same timer. For a given Field 2 duration, target-alone and target-in-context runs were consecutive, with the order randomized between the two Ss (the authors). In all, each $S$ provided 30 readings for each target at each duration with each context and 40 readings for each target alone at each duration.

\section{RESULTS}

The results of this experiment are shown in Fig. 1. Probability of recognition has been averaged across the four target letters and is not corrected for guessing. The four functions represent performance with no context and with each of the three context fields plotted separately. In contrast to expectations based upon previous research, we find that the presence of the context improves letter recognition. There is no indication in these data of any systematic differences in recognition with different contexts.

To determine if this facilitatory effect was statistically significant, a chi-square test was applied to the recognition frequencies at each target duration with $\alpha=0.05$. At the lower end of the psychometric functions, where performance approaches chance level, no significant facilitatory effect is found. Above $45 \%$ correct recognition, the difference between the target alone and the context 


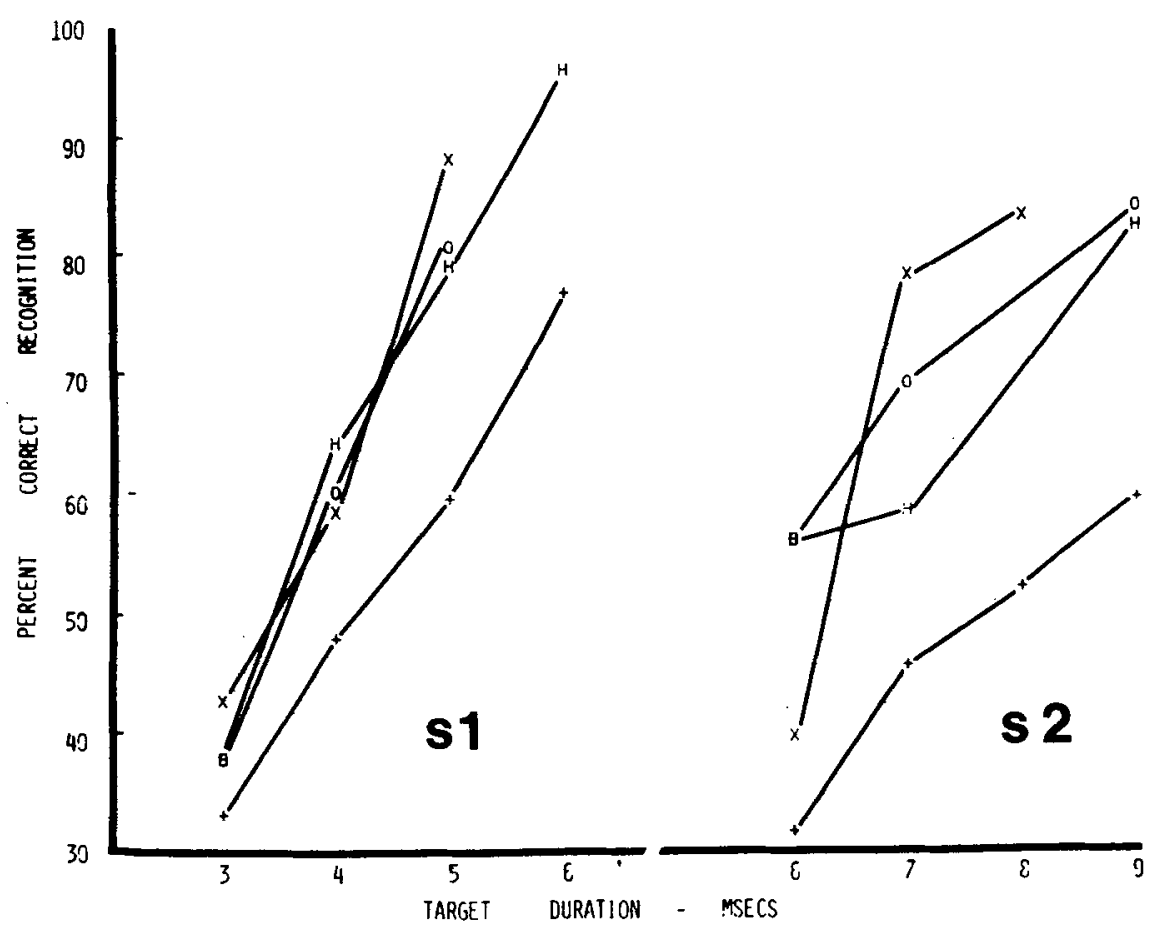

Fig. 1. Percent correct target letter recognition as a function of stimulus duration for two Ss. $\mathrm{O}, \mathrm{H}$, and $\mathrm{X}$ refer to respective context conditions; + refers to target presented alone.

condition is always significant for both Ss except for the $X$ context at 4 msec for $\mathbf{S} 1$.

To determine if a particular context was interacting in the same manner with each target letter and if the facilitation was due to sensory or criterial change, we analyzed the data in the following way. For $S 1$ we totaled the number of correct recognitions for individual letters for each condition at 3,4 , and $5 \mathrm{msec}$; from this, an average probability of recognition was obtained. We then counted the number of "false alarms" for these times by taking the number of times a particular letter response was obtained when that letter was not presented. This procedure enabled us to calculate an overall respondent rate for each letter, e.g., P(A/EOU). From the correct recognition probability and the false alarm rate, an index of sensitivity based upon d' tables has been calculated for each letter for each of the four stimulus conditions. ${ }^{1} \mathrm{~A}$ similar operation was performed for $S 2$, using the durations of $6,7,8$, and 9 msec.

The results of these computations are shown in Table 1. Looking at the data for the target alone we find a greater sensitivity and also higher false-alarm rate for $O$ and $U$ than for $A$ and $E$ for both Ss. The greatest effect of facilitation is found with a $U$ target in a row of $\mathrm{Hs}$, but this is not accompanied by an increased false-alarm rate. Each $S$ shows the same overall trend in facilitation, e.g., $\boldsymbol{O}$ is generally least affected by the context followed by $\mathbf{E}, \mathbf{A}$, and $U$, in that order. False-alarm rates are fairly constant across the four conditions for $A$ and $E$, while there is a drop in the number of $\mathbf{O}$ and $\mathbf{U}$ false alarms from the target-alone to the context conditions. Generally, there is little systematic evidence for changes in either sensitivity or false-alarm rates with different letter-mask combinations.
A rank-order correlation for each $\mathrm{S}$ between the increase in $d^{\prime}$ for each letter attributable to the context and the minimum contour separation of the corresponding target and context did not approach statistical significance (S 1, $\rho=-0.09 ; \quad S 2$, $\rho=+0.07$ ). Any effect of spatial interactions of contours is probably more complex than this simple measure of contour proximity reveals.

To check whether or not the number of letters in the context was important for producing the facilitatory effect, we ran the two Ss with only one $O$ on each side of the target, as well as with four Os on each side; again, a target-alone condition was run to determine base performance level. The psychophysical procedure was identical to the first experiment, with the exception that the three conditions were now randomized for each $\mathrm{S}$. We obtained 30 readings for each letter for each of the conditions. While the facilitatory effect was obtained with both contexts, the results of the two Ss in this case failed to agree about the effect of context length. In order to resolve this issue and to test the reliability and repeatability of the facilitatory effect found for the authors, five naive $S s$ were tested. Eight-O and two-O context and target-alone conditions were investigated. Each $S$ performed the experiment at one stimulus duration only, selected to yield intermediate recognition probabilities. For each $\mathbf{S}$, 120 trials were run in each condition, using the previously described procedures.

Results for the five naive $S s$ are given in Table 2. Each of the $S$ s confirms the original finding that the presence of the context facilitates recognition. A chi-square test showed

Table 1

Calculated $d^{\prime}$ and False Alarm Rates for Sinjle Letter

\begin{tabular}{|c|c|c|c|c|c|}
\hline & & \multicolumn{2}{|c|}{ S 1} & \multicolumn{2}{|c|}{ S 2} \\
\hline & & $d$ & $\begin{array}{l}\text { False } \\
\text { Alarm } \\
\text { Rate }\end{array}$ & $\mathbf{d}^{\prime}$ & $\begin{array}{l}\text { False } \\
\text { Alarm } \\
\text { Rate }\end{array}$ \\
\hline $\begin{array}{l}\text { Target } \\
\text { Letter } \\
\text { Alone }\end{array}$ & $\begin{array}{l}\mathbf{A} \\
\mathbf{E} \\
\mathbf{O} \\
\mathbf{U}\end{array}$ & $\begin{array}{l}0.67 \\
0.84 \\
1.00 \\
0.88\end{array}$ & $\begin{array}{l}0.14 \\
0.16 \\
0.22 \\
0.19\end{array}$ & $\begin{array}{l}0.72 \\
0.62 \\
1.02 \\
1.08\end{array}$ & $\begin{array}{l}0.13 \\
0.12 \\
0.17 \\
0.26\end{array}$ \\
\hline "O" Context & $\begin{array}{l}\mathbf{A} \\
\mathbf{D} \\
\mathbf{0} \\
\mathbf{U}\end{array}$ & $\begin{array}{l}1.52 \\
1.14 \\
1.57 \\
1.46\end{array}$ & $\begin{array}{l}0.09 \\
0.18 \\
0.13 \\
0.11\end{array}$ & $\begin{array}{l}1.51 \\
1.13 \\
1.36 \\
1.67\end{array}$ & $\begin{array}{l}0.15 \\
0.13 \\
0.13 \\
0.11\end{array}$ \\
\hline "H" Context & $\begin{array}{l}\mathbf{A} \\
\mathbf{E} \\
\mathbf{O} \\
\mathbf{U}\end{array}$ & $\begin{array}{l}1.38 \\
1.42 \\
1.28 \\
2.58\end{array}$ & $\begin{array}{l}0.11 \\
0.17 \\
0.13 \\
0.08\end{array}$ & $\begin{array}{l}1.60 \\
1.50 \\
1.62 \\
2.08\end{array}$ & $\begin{array}{l}0.13 \\
0.12 \\
0.17 \\
0.10\end{array}$ \\
\hline "X" Context & $\begin{array}{l}\mathbf{A} \\
\mathbf{E} \\
\mathbf{O} \\
\mathbf{U}\end{array}$ & $\begin{array}{l}1.25 \\
1.49 \\
1.66 \\
1.75\end{array}$ & $\begin{array}{l}0.12 \\
0.13 \\
0.13 \\
0.10\end{array}$ & $\begin{array}{l}1.79 \\
1.04 \\
1.72 \\
1.90\end{array}$ & $\begin{array}{l}0.17 \\
0.12 \\
0.10 \\
0.09\end{array}$ \\
\hline
\end{tabular}


Table 2

Percent Correct Target Letter Recognition for Five Naive Ss for Target Alone and Two Context Conditions

\begin{tabular}{llllll}
\hline \multicolumn{1}{c}{ Condition } & RG & MS & KL & NG & SH \\
\hline Target Alone & 45 & 45 & 63 & 50 & 42 \\
2- "O" Context & $59^{*}$ & 53 & $78 *$ & $7^{* *}$ & 53 \\
$8-$ - "O" Context & $62^{* *}$ & $65^{* *}$ & $8^{* *}$ & $7^{* *}$ & 48 \\
\hline
\end{tabular}

A chi-square test was performed on the difference between recognition scores with target alone and each of the context conditions; * indicates $p<.05, * *$ indicates $p<.01$.

these results to be significant $(p<.01$ ) for four of the five Ss. The two-O context also appears to facilitate recognition, though the chi-square test suggests that this effect is less reliable.

\section{DISCUSSION}

In summary, flanking letters are found to improve the recognition of a foveal target letter. In considering what type of process may be responsible for this effect, two broad classes of explanation suggest themselves. A sensory explanation would be in terms of relationships between space, time, and luminance. More cognitive explanations would involve a linguistic or feature analysis level of processing or a consideration of the effect in terms of reduction of spatial or temporal uncertainty. A linguistic or feature comparison explanation would require that the magnitude of the facilitatory effect depend on the specific target/context combination. The data in Table 1 show little evidence for such specificity. In addition, the fact that the presence of a context has an opposite, i.e., inhibitory, ef fect in the periphery (Woodworth, 1948; Bouma, 1970) also militates against these explanations. Currently, we are using a proximal edge as a context to adjudicate this issue more directly. The uncertainty hypothesis attributes to the context the properties of a spatial or temporal marker, which serves to improve performance through a reduction in uncertainty of the exact position in time or space when the target appears. Our finding (Henderson \& Matthews, 1970), that the facilitatory effect was a nonmonotonic function of the context proximity, suggests that uncertainty alone cannot account for the effect.

The simplest form that a sensory explanation might take would be to consider that the effective luminance of the target (and hence its detectability) is reduced by the inhibitory effect of a bright surround. The effect of the context would be facilitatory, due to a reduction of the luminance of the bright surround in the vicinity of the target. The finding (Eriksen \& Collins, 1964) that a surrounding black annulus inhibits letter detectability would seem to contradict this hypothesis: However, the time and contrast values reported in the latter study differ considerably from the values we have used. Other forms of sensory explanation might consider the spatial interaction in terms of contour processes rather than simple energy relationships. Adjudication between these possibilities must await further studies in which the nature of the target and context, their contrast, and their proximity are systematically varied. While we have been unable to find a directly comparable study, the results presented here run counter to generalized expectations based on the literature on masking. An issue yet to be resolved is the generality of the facilitatory effect with other values of the experimental parameters.
Nevertheless, whatever the generality of the effect, any explanation of spatial letter interactions must account for both facilitatory and inhibitory effects.

Finally, returning to the immediate recall paradigm, the obtained "W"-shaped function is predictable from the assumption that the direction of the metacontrast effect changes from fovea to periphery without recourse to considerations of spatial variations of acuity.

\section{REFERENCES}

AVERABCH, E. \& CORIELL, A. S. Short term memory in vision. Bell System Technical Journal, 1961, 40, 309-328.

BOUMA, H. Interaction effects in parafoveal letter recognition. Nature, $1970,226,177.178$.

COLTHEART, M., \& MERIKLE; P. M. Do visual half-field differences in the report of briefly exposed rows of letters occur because subjects process such material from left to right? Paper presented to C.P.A., Winnipeg, 1970.

ERIKSEN, C. W., \& COLLINS, J. F. Investigation of the effect of a priming stimulus on backward masking. Psychonomic Science, 1964, 1, 249-250. FLOM, M. C., WEYMOUTH, F. W., \& KAHNMAN, D. Visual resolution and contour interaction. Journal of the Optical Society of America, 1963, 53, 1026-1032.

HABER, R. N., \& STANDING, L. Location of errors with a poststimulus indicator. Psychonomic Science, 1969, 17, 345-346.

HENDERSON, L., \& MATTHEWS, M. L. Foveal letter recognition: Masking unmasked. Paper presented to Psychonomic Society, San Antonio, 1970.

RUEDIGER, W. C. (1907), quoted in Woodworth, R. S. Experimental psychology. New York: Holt, 1948.

WEYMOUTH, F. W. Visual sensory units and the minimum angle of resolution. American Journal of Ophthalmology, $1958,46,102-113$.

WOODWORTH, R. S. Experimental psychology. New York: Holt, 1948. NOTE

1. It should be noted that a faise alarm rate derived from a forced-choice procedure is not entirely independent of sensitivity. Nevertheless, for comparison between letters, these measures provide relative information concerning sensitivity and criterion values. 